\title{
Unraveling the Complexity of Critical Consciousness, Political Efficacy, and Political Action Among Marginalized Adolescents
}

\author{
Matthew A. Diemer and Luke J. Rapa \\ University of Michigan and Michigan State University
}

\begin{abstract}
This research examines the complex patterns by which distinct dimensions of critical consciousness may lead marginalized adolescents toward distinct forms of political action. Structural equation modeling was applied to nationally representative data from the Civic Education Study (2,811 ninth graders; $\left.M_{\text {age }}=14.6\right)$, first establishing the measurement invariance of constructs across samples of poor or working class African American and Latino/a adolescents. Perceptions of societal inequality and aspirational beliefs that society ought to be more equal differentially predicted expected voting, conventional political action, and social action-while controlling for civic achievement and with nuances between ethnic and racial groups. Contrary to hypotheses and extant scholarship, political efficacy did not mediate or moderate relations between critical reflection and disparate forms of political action.
\end{abstract}

This article examines the complex patterns by which distinct dimensions of critical consciousness (CC) may lead marginalized adolescents toward distinct forms of political action. Marginalized youth, defined here as poor and working class adolescents of color, encounter a variety of structural constraints that limit their agency as well as their participation in broader societal and political institutions (American Political Science Association, Task Force on Inequality and American Democracy, 2004; Flanagan, 2013). CC is composed of critical reflection (e.g., a careful analysis of structural inequalities and the endorsement of group equality), political efficacy (e.g., the perceived capacity to effect social and political change), and critical action (e.g., individual or collective action to change societal inequities) components (Watts, Diemer, \& Voight, 2011). CC is theorized to provide marginalized and/or oppressed people with the agency to overcome structural constraints (Freire, 1973, 1993; Watts et al., 2011) and has been called the "antidote to oppression" (Watts, Griffith, \& Abdul-Adil, 1999).

The present research advances previous inquiry by specifically decomposing the three components of CC. This yields a more precise and nuanced portrait of how different aspects of CC may be associated with different forms of civic and political action among marginalized youth. In contrast, previous research has relied upon an undifferentiated

Correspondence concerning this article should be addressed to Matthew Diemer, Room 4120, School of Education, Ann Arbor, MI 48109. Electronic mail may be sent to diemerm@umich.edu. conceptualization of CC that blends its critical reflection and critical action dimensions (Diemer, 2012; Gordon, 2007; Taft, 2006) or only examines one component in isolation (e.g., critical action in Diemer \& Li, 2011). This clouds our understanding of how distinct CC components, as well as distinctions among the subcomponents of critical reflection, may be predictive of different forms of civic and political action among marginalized adolescents.

Furthermore, much of the literature exploring the relation between CC and conventional political participation rests on a "never the twain shall meet" assumption-that critically conscious young people choose to engage only in activism rather than more conventional forms of political behavior (see Diemer \& Li, 2011, for a review). However, this assumption may be a by-product of how CC has been measured in previous research rather than an accurate assessment of how CC may engender different forms of political action. It may be that critically analyzing ethnic-racial and gender disparities in educational and occupational opportunity may engender social movement activism to change these inequalities. On the other hand, critically reflecting on how groups in society should be equal (a cornerstone of the U.S. Constitution) may engender more conventional political participation to promote equality (e.g., voting and writing letters to elected

(C) 2015 The Authors

Child Development (C) 2015 Society for Research in Child Development, Inc. All rights reserved. 0009-3920/2016/8701-0019

DOI: $10.1111 /$ cdev. 12446 
officials), which is more consistent with mainstream democratic ethos. The comprehensive measurement of CC in this research, as well as including distinct forms of political action, allows for testing these potentially distinct pathways among marginalized adolescents.

This research also extends previous inquiry by examining whether political efficacy may mediate or moderate the relation between critical reflection and critical action, as suggested by extant CC theory (Freire, 1973, 1993; Watts et al., 2011). It is argued that the perceived capacity to effect change may delineate "armchair activists" (e.g., people who perceive societal inequities yet do not engage in action) from those who are participatory (e.g., people who perceive societal inequities who do participate in social action). The notion that critical reflection begets feelings of agency and efficacy, which in turn leads to critical action, is a central tenet of CC theory. Yet, this reciprocal relation has been subject to little empirical scrutiny. This research examines whether political efficacy serves a mediating roleif critical reflection predicts political efficacy and, in turn, if political efficacy predicts critical action-or if political efficacy serves a moderating role, to address this knowledge gap.

\section{Theoretical Framework}

\section{Conceptualizing CC}

CC, the analysis of one's social conditions and taking action to change perceived inequities, is argued to provide marginalized and oppressed people with the capacity to overcome structural constraints (Freire, 1973, 1993; Watts et al., 1999). Freire (1993) viewed CC as "reflection and action upon the world in order to transform it" (p. 51). To review, CC is composed of critical reflection, political efficacy, and critical action subcomponents; these subcomponents are believed to reciprocally influence each other. Critical reflection is composed of two subcomponents (Diemer, Rapa, Park, \& Perry, 2014). Critical reflection: perceived inequality refers to a critical analysis of social inequalities, such as ethnic-racial, gendered, and socioeconomic constraints on educational and occupational opportunity (Diemer et al., 2014; Godfrey \& Grayman, 2014). Critical reflection: egalitarianism refers to the endorsement of equality between groups in a society (Diemer \& Blustein, 2006; Freire, 1993).

Political efficacy is also decomposed into two component parts. Internal political efficacy is the perceived capacity to effect social and political change via individual and/or collective action (Watts et al., 2011), consistent with the political science tradition (Niemi, Craig, \& Mattei, 1991). In contrast, external political efficacy refers to perceptions that political officials and government are responsive to one's interests and needs (Kahne \& Westheimer, 2006). Although external political efficacy is not considered a component of CC, we know little about how it may relate to youth's political commitments (Flanagan, 2013). What few studies exist suggest that perceptions of governmental responsiveness may uniquely shape pathways to political participation (Kahne \& Westheimer, 2006) and this is therefore examined here as well. For example, the perception that government was less responsive to one's interests and demands was associated with societal activism among African American adults (Shingles, 1981).

Critical action refers to participation in individual or collective action to produce social change (Godfrey \& Grayman, 2014). Protest, or collective action taken to draw attention to an issue or to protest perceived injustice, is an archetypal form of critical action (Gordon, 2007; Taft, 2006; Watts \& Flanagan, 2007) that is examined in this research. (For clarity, this construct is referred to as critical action: protest from this point forward.)

Developmental scholarship has argued that expectations or commitments to be participatory are more developmentally sensitive conceptions of social and political action among adolescents, given the many barriers to formal political and social action participation that they face (e.g., Kirshner, 2009; Watts \& Flanagan, 2007). In this research, we therefore examined early adolescents' expected political and critical action participation in the future, as their opportunities for actual participation in the present are more limited.

\section{Intersections of CC and Political Action}

Research has yielded mixed evidence regarding the relation between CC and political action. Critical reflection: perceived inequality has been linked to social action rather than conventional political participation, such as voting. Westheimer and Kahne (2004) found that critically conscious urban youth expressed a commitment to a distinct form of citizenship, such that adolescents exhibiting greater levels of critical reflection (i.e., were more aware of perceived social inequalities) are more committed to activism than to conventional political action. Ethnographies also suggest that adolescent activists with greater perceptions of societal inequities are 
more committed to social action participation than conventional political participation (Gordon, 2007; Taft, 2006). Finally, greater levels of CC-although in this case reflecting an undifferentiated conception of critical reflection and action-were not predictive of marginalized youth's conventional political participation (Diemer, 2012).

Other inquiry has countered the "never the twain shall meet" perspective (i.e., that young people who critically perceive societal inequities are less likely to engage in conventional political behavior). Related scholarship suggests, but does not empirically examine, that marginalized adolescents with greater levels of perceived inequality would be more likely to engage in conventional political action (Watts \& Flanagan, 2007; Youniss \& Yates, 1997). Marginalized youth with greater levels of critical action (e.g., participation in social action groups, protests, peaceful marches, and/or boycotts) were also more likely to vote (Diemer \& Li, 2011), although critical reflection: perceived inequality was not examined in that study. Furthermore, the relation between critical reflection: egalitarianism and distinct forms of political participation (i.e., activism vs. voting) has not been empirically examined. In sum, a paucity of research has examined how distinct forms of CC may predict different forms of participation.

To extend existing research, this study examines associations between critical reflection: egalitarianism and critical reflection: perceived inequality as well as conventional and nonconventional forms of political action. CC theory would suggest that both critical reflection components predict engagement in critical action: protest, a nonconventional form of political participation (Freire, 1993; Watts et al., 2011). Because CC is believed to unlock human agency among marginalized people, both components would also be expected to predict more conventional forms of political action and voting (Watts et al., 1999). However, the precise specification of critical reflection, unique to this study, might reveal that these two distinct components of critical reflection differentially predict conventional participation versus critical action: protest. It may also be that critical reflection: egalitarianism and critical reflection: perceived inequality differentially predict internal and external political efficacy. Perceptions of structural inequality may be associated with perceptions that government is less responsive to the interests of less powerful groups in society (Flanagan, 2013). On the other hand, aspirational beliefs that society ought to be more equal may make young people feel more empowered to create social change (Diemer et al., 2014; Watts et al., 2011). Internal and external political efficacy themselves may each lead, in turn, to differentiated participation in conventional and nonconventional political action, respectively. That is, internal and external political efficacy may mediate and/or moderate the relation between critical reflection and conventional and nonconventional (i.e., protest) political participation (Shingles, 1981; Watts \& Flanagan, 2007).

\section{Study Hypotheses}

Figure 1 depicts hypothesized relations among latent constructs, examined using structural equation modeling (SEM). Moving left to right in the figure, critical reflection: egalitarianism is hypothesized to predict internal political efficacy, expected conventional political action, expected voting, and critical action: protest. Critical reflection: perceived inequality is hypothesized to predict internal political efficacy, external political efficacy, expected conventional political action and expected voting, and critical action: protest. Critical reflection: egalitarianism is expected to correlate with critical reflection: perceived inequality. Internal political efficacy is expected to predict conventional political action, expected voting, and critical action: protest. External political efficacy is hypothesized to predict critical action: protest. Internal political efficacy and external political efficacy are expected to correlate. Conventional political action is hypothesized to correlate with expected voting, while expected voting is hypothesized to correlate with critical action: protest. Finally, conventional political action is expected to correlate with critical action: protest. The conceptualization and measurement of these constructs are detailed below.

A large literature indicates that those who feel more knowledgeable about political and social issues are more likely to participate in political action (e.g., American Political Science Association, Task Force on Inequality and American Democracy, 2004). Civic/political knowledge may also predict youth's critical reflection (e.g., those who know more about sociopolitical issues may have greater recognition of sociopolitical inequalities), political efficacy, and critical action: protest (Diemer \& Li, 2011; Flanagan, 2013). Civic/political knowledge is therefore controlled for by regressing all other latent constructs onto this variable (Kline, 2010); for the sake of clarity, these paths are not depicted in the figures. Assuming that this key observed confounder may correlate with some unobserved confounding variables that 


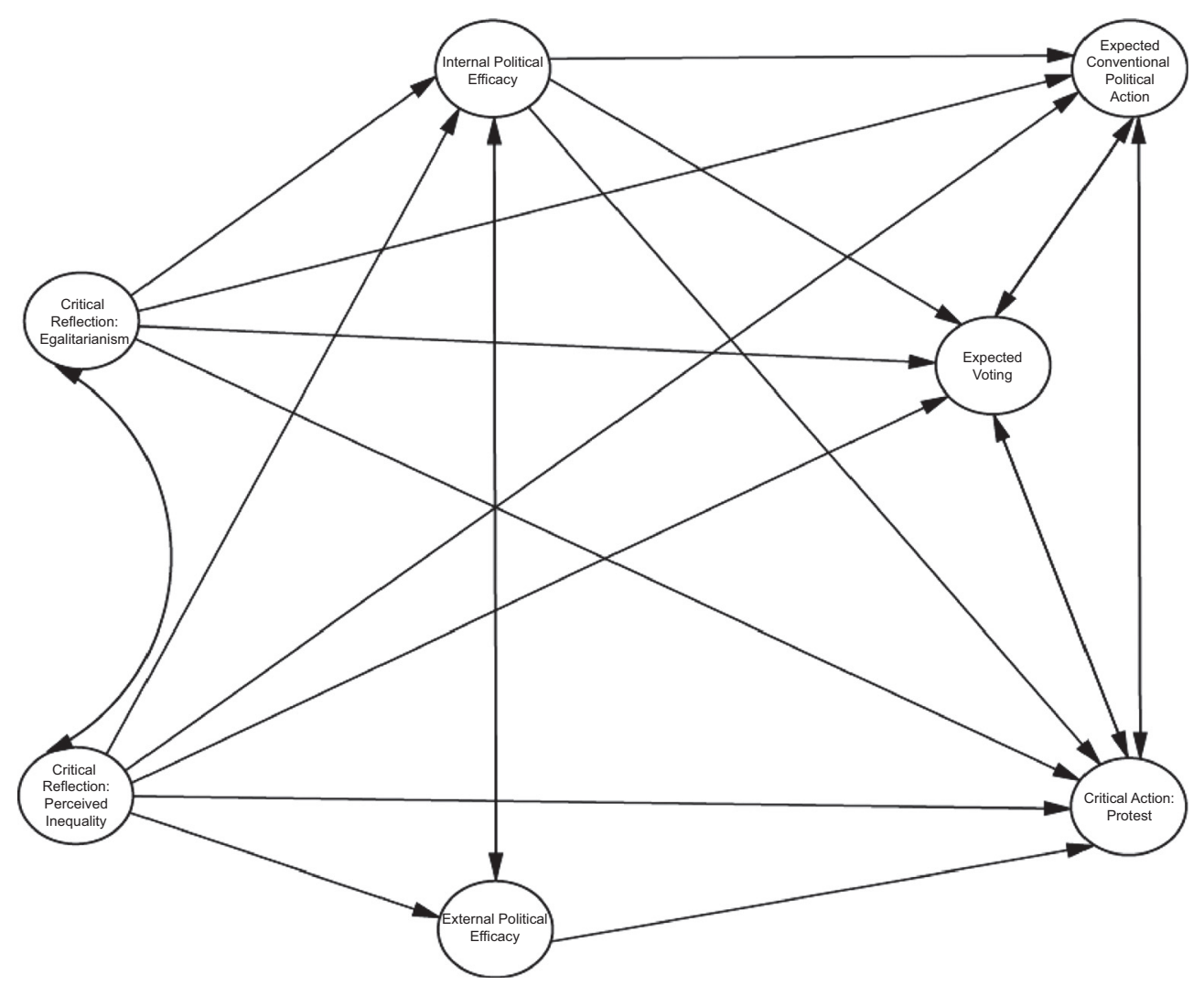

Figure 1. Conceptual model.

cannot be measured and controlled, this approach may also partially address omitted variables bias (Shadish, Clark, \& Steiner, 2008).

\section{Method Sample}

This study draws from the nationally representative population of 2,811 ninth graders $\left(M_{\text {age }}=14.6\right)$ from 150 U.S. schools who participated in the Civic Education Study of 1999 (CIVED). The International Association for the Evaluation of Educational Achievement (IEA) designed CIVED to explore the civic education and attitudes of adolescents in approximately 30 countries. Among other things, CIVED measured youth's knowledge of democracy and citizenship, their attitudes about their nation and its institutions, and expectations for future civic and political participation.

The U.S. population of 2,811 CIVED participants was composed of an equal proportion of young women and young men ( $49.9 \%$ female). The CIVED questionnaire asked participants to identify their ethnicity (i.e., "Hispanic or Latino" or "Not Hispanic or Latino"; those indicating a "Hispanic or Latino" ethnicity are hereafter referred to as Latino/a) along with their racial group affiliation (i.e., "Native American or Alaskan Native," "Asian," "Black or African American," or "White"). The challenge associated with differentiating between ethnic and racial identity is well documented (Rivas-Drake et al., 2014). In order to establish discrete ethnic-racial identity (ERI) categories, we established a superordinate ERI variable (RivasDrake et al., 2014). According to this ERI categorization, participants who identified as Latino/a were included in one ERI category, regardless of their racial group identification. Similarly, anyone who identified as having more than one racial group affiliation (but did not identify as "Hispanic or Latino") was classified as multiracial. Other ERI categorizations were based on participants' racial group identification. Overall, 1,126 (40.1\%) participants identified as a person of color, $1,597(56.8 \%)$ as White, $430(15.3 \%)$ as Latino/a, $429(15.3 \%)$ as Black or African American, 106 (3.8\%) as Asian, 93 $(3.3 \%)$ as multiracial, $45(1.6 \%)$ as Native Hawaiian 
or Pacific Islander, and $23(0.8 \%)$ as Native American or Alaskan Native.

A subpopulation of poor and working class youth of color was created, under the assumption that these youth encounter heightened racialized and socioeconomic marginalization and discrimination (Watts \& Flanagan, 2007). Because these participants were only in ninth grade, the social class position of their parents was used to determine these adolescents' social class (Diemer, Mistry, Wadsworth, López, \& Reimers, 2013). The highest level of education that each participant's mother attained was used to measure social class. Maternal education is also a marker of social inclusion and access to social and cultural capital among the more privileged social classes (Diemer et al., 2013) that is predictive of political participation (American Political Science Association, Task Force on Inequality and American Democracy, 2004; Gordon, 2007). Only participants whose mothers' highest level of educational attainment was post-high school vocational training or enrolling in some postsecondary courses, but not completing a bachelor's degree, were selected to represent poor and working class status.

Our focal subpopulation of CIVED participants consisted of 761 poor and working class African American $(n=367)$ and Latino/a $(n=394)$ youth. Other ERI groups, such as Asian youth $(n=81)$, did not provide sufficient sample sizes to ensure statistical power. (The Westland, 2010, innovative power calculation for SEM, the $r$ ratio, indicated that a sample of $n=166$ would be required to provide sufficient power [calculations not depicted here to conserve space; please contact the first author for more information].) The identified African American and Latino/a subpopulation sample sizes were well above this level.

\section{Measures}

The CIVED user's guide and an IEA-sponsored technical report detail confirmatory factor and item response theory (IRT) analyses of CIVED, yielding several well-validated scales (see Husfeldt, Barber, \& Torney-Purta, 2005; Torney-Purta, Lehmann, Oswald, \& Schulz, 2001). This same constellation of CIVED items measuring latent constructs was followed to operationalize several constructs in the present study: internal political efficacy, conventional political action, voting, and critical action: protest. Godfrey and Grayman (2014) used these same CIVED items to measure external political efficacy, although that research labeled this construct "perceptions of government responsiveness." Despite using the same items, we have elected to label this construct "external political efficacy" in this research, given the long history (in political science and beyond) of measuring external political efficacy with the same or similar items (see Kahne \& Westheimer, 2006; Niemi et al., 1991; Shingles, 1981).

The present study developed new measures of critical reflection: perceived inequality and critical reflection: egalitarianism, conceptually grounding each new measure in the CC literature (e.g., Diemer \& Blustein, 2006; Watts et al., 2011). In addition, the specific CIVED items used were identical to or highly similar to the items used to measure critical reflection in a recently validated Critical Consciousness Scale. All four CIVED indicators of critical reflection: perceived inequality in the present study were used as items to measure critical reflection: perceived inequality in the Critical Consciousness Scale (Diemer et al., 2014). The CIVED items measuring critical reflection: egalitarianism are highly similar to the items measuring this same construct in the Critical Consciousness Scale. For example, the CIVED item "All ethnic and racial groups should have equal chances at education" is highly similar to the Critical Consciousness Scale item "All groups should be given an equal chance in life" (Diemer et al., 2014).

This measure of "critical action: protest" was labeled "protest participation" in the CIVED documentation. This measure was retitled to conform to the CC theoretical framework-protest is an important dimension of critical action (Diemer et al., 2014; Thomas et al., 2014; Watts et al., 2011). The critical action: protest CIVED items, which ask about spray painting protest slogans, occupying buildings, and blocking traffic as forms of protest, are specific examples of how critical action (e.g., "How frequently have you joined in a protest march, demonstration, or political meeting?") is measured in the Critical Consciousness Scale as well as how critical action was operationalized (e.g., "Have you ever taken part in a protest march, meeting, or demonstration?") in previous analyses of survey data sets (Diemer \& Li, 2011).

Each measure is briefly reviewed below; further detail about each latent construct, items, and descriptive data is provided in Table 1 .

Critical reflection: egalitarianism (measured by three items) refers to the endorsement of societal equality, or the idea that all groups of people within society should be treated equally (Diemer \& Blustein, 2006; Diemer et al., 2014). The 
Table 1

Variables List and Descriptive Data

\begin{tabular}{|c|c|c|c|c|c|}
\hline \multirow[b]{2}{*}{ Latent variable/indicators and descriptions } & \multirow[b]{2}{*}{ Possible responses } & \multicolumn{2}{|c|}{$\begin{array}{l}\text { Latino/a } \\
(n=394)\end{array}$} & \multicolumn{2}{|c|}{$\begin{array}{l}\text { African } \\
\text { American } \\
(n=367)\end{array}$} \\
\hline & & $M$ & $S D$ & $M$ & $S D$ \\
\hline \multicolumn{6}{|l|}{ Critical reflection: egalitarianism } \\
\hline $\begin{array}{l}\text { BS4G2-All ethnic and racial groups should have equal chances } \\
\text { at education. }\end{array}$ & $\begin{array}{l}1 \text { = strongly disagree } \\
2 \text { = disagree }\end{array}$ & 3.47 & 0.72 & 3.36 & 0.79 \\
\hline $\begin{array}{l}\text { BS4G5-All ethnic and racial groups should have equal chances } \\
\text { at jobs. }\end{array}$ & $\begin{array}{l}3=\text { agree } \\
4=\text { strongly agree }\end{array}$ & 3.46 & 0.78 & 3.32 & 0.88 \\
\hline $\begin{array}{l}\text { BS4G8 - Schools should teach students to respect members of all } \\
\text { ethnic and racial groups. }\end{array}$ & & 3.24 & 0.87 & 3.16 & 0.89 \\
\hline \multicolumn{6}{|l|}{ Critical reflection: perceived inequality } \\
\hline $\begin{array}{l}\text { BS4F1 - Children who are members of certain racial or ethnic } \\
\text { groups have fewer chances than other children to get a good high } \\
\text { school education in this country. }\end{array}$ & $\begin{array}{l}1=\text { strongly disagree } \\
2 \text { = disagree } \\
3 \text { = agree }\end{array}$ & 2.02 & 0.95 & 2.33 & 1.01 \\
\hline $\begin{array}{l}\text { BS4F3 - Children from poor families have fewer chances than } \\
\text { others to get a good high school education in this country. }\end{array}$ & $4=$ strongly agree & 2.08 & 0.99 & 2.22 & 1.04 \\
\hline $\begin{array}{l}\text { BS4F5-Adults who are members of certain racial or ethnic groups } \\
\text { have fewer chances than others to get good jobs in this country. }\end{array}$ & & 2.22 & 0.94 & 2.41 & 0.99 \\
\hline $\begin{array}{l}\text { BS4F6-Women have fewer chances than men to get good jobs } \\
\text { in this country. }\end{array}$ & & 2.08 & 1.00 & 2.11 & 1.02 \\
\hline \multicolumn{6}{|l|}{ Internal political efficacy } \\
\hline BS4I2-I know more about politics than most people of my age. & 1 = strongly disagree, & 2.04 & 0.80 & 2.22 & 0.91 \\
\hline $\begin{array}{l}\text { BS4I5-When political issues or problems are being discussed, } \\
\text { I usually have something to say. }\end{array}$ & $\begin{array}{l}2=\text { disagree } \\
3=\text { agree }\end{array}$ & 2.61 & 0.91 & 2.62 & 0.89 \\
\hline BS4I8-I am able to understand most political issues easily. & $4=$ strongly agree & 2.53 & 0.81 & 2.64 & 0.87 \\
\hline BS4I10-I am interested in politics. & & 2.16 & 0.98 & 2.27 & 0.99 \\
\hline \multicolumn{6}{|l|}{ External political efficacy } \\
\hline $\begin{array}{l}\text { BS4I4 -The powerful leaders in government care very little about } \\
\text { the opinions of people (reverse coded) }\end{array}$ & $\begin{array}{l}1=\text { strongly disagree } \\
2 \text { = disagree }\end{array}$ & 2.67 & 0.83 & 2.64 & 0.90 \\
\hline $\begin{array}{l}\text { BS4I6-In this country, a few individuals have a lot of political } \\
\text { power while the rest of the people have very little power (reverse } \\
\text { coded) }\end{array}$ & $\begin{array}{l}3=\text { agree } \\
4=\text { strongly agree }\end{array}$ & 2.72 & 0.82 & 2.77 & 0.88 \\
\hline $\begin{array}{l}\text { BS4I7-The politicians quickly forget the needs of the voters who } \\
\text { elected them (reverse coded) }\end{array}$ & & 2.89 & 0.85 & 2.78 & 0.89 \\
\hline \multicolumn{6}{|l|}{ Expected conventional political action } \\
\hline $\begin{array}{l}\text { BS5M3-When you are an adult, what do you expect that you } \\
\text { will do? Join a political party. }\end{array}$ & $\begin{array}{l}1=\text { certainly not do this } \\
2=\text { probably not }\end{array}$ & 1.92 & 0.85 & 1.96 & 0.92 \\
\hline $\begin{array}{l}\text { BS5M4 - When you are an adult, what do you expect that you } \\
\text { will do? Write letters to a newspaper about social or political } \\
\text { concerns. }\end{array}$ & $\begin{array}{l}3=\text { probably will, } \\
4=\text { certainly will }\end{array}$ & 2.06 & 0.89 & 2.03 & 0.90 \\
\hline \multicolumn{6}{|l|}{ Expected voting } \\
\hline $\begin{array}{l}\text { BS5M1-When you are an adult, what do you expect that you } \\
\text { will do? Vote in national elections. }\end{array}$ & $\begin{array}{l}1=\text { certainly not do this } \\
2=\text { probably not }\end{array}$ & 2.87 & 0.97 & 2.99 & 0.86 \\
\hline $\begin{array}{l}\text { BS5M2-When you are an adult, what do you expect that you } \\
\text { will do? Get information about candidates before voting in an } \\
\text { election. }\end{array}$ & $\begin{array}{l}3=\text { probably will, } \\
4=\text { certainly will }\end{array}$ & 2.94 & 1.02 & 2.89 & 0.95 \\
\hline \multicolumn{6}{|l|}{ Critical action: protest } \\
\hline $\begin{array}{l}\text { BS5M10-Do you expect that you will spray paint protest slogans } \\
\text { on walls? }\end{array}$ & $\begin{array}{l}1=\text { certainly not do this } \\
2=\text { probably not }\end{array}$ & 1.85 & 0.98 & 1.72 & 0.96 \\
\hline $\begin{array}{l}\text { BS5M11-Do you expect that you will block traffic as a form of } \\
\text { protest? }\end{array}$ & $\begin{array}{l}3=\text { probably will, } \\
4=\text { certainly will }\end{array}$ & 1.78 & 0.93 & 1.63 & 0.88 \\
\hline $\begin{array}{l}\text { BS5M12-Do you expect that you will occupy public buildings } \\
\text { as a form of protest? }\end{array}$ & & 1.75 & 0.88 & 1.74 & 0.93 \\
\hline
\end{tabular}


internal consistency of the three critical reflection: egalitarianism items was good, with a Cronbach's alpha of .73 and a mean interitem correlation of .47. However, Cronbach's alpha is a misleading estimate of internal consistency (i.e., it is downwardly biased) when a measure consists of few items, because the calculation of alpha is overly sensitive to the number of items in a measure (DeVellis, 2003; Streiner, 2003). Mean interitem correlations, which provide more accurate estimates of internal consistency that are not biased by the number of items per measure, are therefore also reported. Generally, good mean interitem correlation values range from 0.15 to 0.50 (Clark \& Watson, 1995). Finally, the use of SEM attenuates concerns regarding internal consistency, in that SEM parcels out measurement error in estimating covariance relations (Kline, 2010).

Critical reflection: perceived inequality (measured by four items) refers to a consciousness of inequalities in educational or occupational opportunities (Diemer et al., 2014). The internal consistency of these four items was good, with a Cronbach's alpha of .78 and a mean interitem correlation of .47.

Internal political efficacy (measured by four items) is the perceived capacity to understand and participate in political processes (Niemi et al., 1991). The internal consistency of these four items was good, with a Cronbach's alpha of .70 and a mean interitem correlation of .37 .

External political efficacy (measured by three items) refers to beliefs that the political system, including the government, its institutions, and political leaders, is responsive to one's interests and the needs of the populace (Niemi et al., 1991). The internal consistency of these three items was lower than other scales in this study and below commonly understood thresholds for acceptable internal consistency (e.g., .70), with a Cronbach's alpha of .53. Internal consistency estimates for this measure may be attenuated because all three CIVED items were reverse coded, which tends to diminish internal consistency estimates (Clark \& Watson, 1995; DeVellis, 2003). However, the mean interitem correlation for these items was 0.27 , squarely within the acceptable range of 0.15-0.50 (Clark \& Watson, 1995). The significant loadings of these items onto the external political efficacy latent construct also provide psychometric support for these items (DeVellis, 2003).

Expected conventional political action (measured by two items) refers to the expectations participants hold for engaging in conventional forms of political participation once they reach adulthood (e.g., Hus- feldt et al., 2005; Torney-Purta et al., 2001). The internal consistency of these two items was good, with a Cronbach's alpha of .68 and a mean interitem correlation of .52 .

Expected voting (measured by two items) refers to the expectations participants hold for engaging in informed voting once they reach adulthood (Diemer \& Li, 2011; Husfeldt et al., 2005). The internal consistency of these two items was good, with a Cronbach's alpha of .78 and a mean interitem correlation of .63.

Critical action: protest (measured by three items) inquires about expected protest participation in the near future, more developmentally appropriate than actual protest participation because youth are excluded from many formal outlets for protest (Watts \& Flanagan, 2007). The internal consistency of these three items was good, with a Cronbach's alpha of .88 and a mean interitem correlation of .70 .

Civic/political knowledge was measured by a CIVED-administered assessment that yielded IRTderived civic achievement scores. This assessment measured both students' civic content knowledge and civic/political interpretive skills across three domains: democracy/citizenship, national identity/ international relations, and social cohesion and diversity (Husfeldt et al., 2005). The score ranges from 9.78 to 162.56 .

\section{Methodological Approach}

SEM simultaneously estimates relations among constructs while adjusting for measurement error and precisely evaluates how well complex models fit the data (Kline, 2010). SEM is particularly useful in secondary analyses, where all aspects of a latent construct may not be measured but available indicators can represent that construct. SEM was used to examine how indicators load onto constructs before modeling relations among constructs, to specify and account for measurement error, to test direct and indirect (i.e., mediated) relations, and to compare plausible alternative models (Kline, 2010).

The IEA employed a complex sampling strategy to ensure that the CIVED sample of 2,811 ninth graders was representative of the entire population of ninth-grade students in the United States in 1999. IEA created a weight variable (named TOTWGT) that adjusts for each participant's probability of being selected into the CIVED sample; weighted analyses of CIVED are nationally representative (Husfeldt et al., 2005). Because the present analyses used this weight variable, these 
findings are representative of all ninth-grade students in the United States.

\section{Testing Measurement Invariance}

Examining the structural model (Figure 1) among African American and Latino/a youth separately presupposes that constructs are measured in the same way and mean the same thing across these two ERI groups. Otherwise, any group differences in the structural model may simply reflect measurement bias. Given the distinct sociopolitical histories and identities of these two ERI groups, it is possible that these constructs may be differentially measured. To examine this proposition, formal tests of measurement invariance (MI) were carried out.

The first step of MI testing requires that one knows the factor structure of constructs, or the measurement model, determined via confirmatory factor analyses (CFA). In estimating model parameters, the weighted least squares mean-and-varianceadjusted estimator was used because the observed variables were all categorical (1-4 Likert-type scaling; see Table 1), save the civic/political knowledge variable. All analyses were carried out under full information maximum likelihood conditions, which uses all existing data points rather than deleting variables listwise or pairwise (Muthén \& Muthén, 2010).

\section{Results \\ Measurement Model}

CFA first determined the pattern of item loadings onto latent constructs. Civic/political knowledge was modeled as an observed variable and therefore excluded from CFA and MI analyses. Conceptual similarity suggested that as two items may share common sources of error variance, the covariance of their error terms should be estimated (external political efficacy items BS4I4 and BS4I7). Substantive concerns primarily guided this estimation of error covariance, though model modification indices also suggested that these two items shared sources of error. These error covariances are included in all subsequent analyses. The hypothesized relations between items and their corresponding latent construct - the measurement model-were a very good fit to the data (see Table 2; comparative fit index $[\mathrm{CFI}]=0.97$, Tucker-Lewis index $[\mathrm{TLI}]=0.96$, root mean square error of approximation [RMSEA] $=0.04)$.
Table 2

Fit Indices for Measurement Model and Tests of Invariance

\begin{tabular}{lccc}
\hline Model fit index & $\begin{array}{c}\text { Measurement } \\
\text { model }\end{array}$ & $\begin{array}{c}\text { Configural } \\
\text { invariance }\end{array}$ & $\begin{array}{c}\text { Factorial and } \\
\text { threshold } \\
\text { invariance }\end{array}$ \\
\hline CFI & 0.97 & 0.96 & 0.96 \\
TLI & 0.96 & 0.95 & 0.96 \\
RMSEA & 0.04 & 0.04 & 0.04 \\
Chi-square value & 375.65 & 566.46 & 614.82 \\
Chi-square diff test & & & 0.15 \\
\hline
\end{tabular}

Note. Chi-square difference test values are only computed for the test of factorial and threshold invariance, in order to compare that model to the configural invariance model. CFI = comparative fit index; TLI = Tucker-Lewis index; RMSEA = root mean square error of approximation.

\section{Establishing $M I$}

Following establishment of the measurement model, testing MI requires sequential tests of configural, factorial, and then threshold (for analyses of categorical observed variables) invariance, described below. Configural invariance examines whether the "configuration" of observed items loading onto a specified latent construct is the same across ERI groups, or whether the same factor structure is measured in each group (Kline, 2010). This configural invariance model serves as the baseline model to which more restrictive models are compared (Schmitt \& Kuljanin, 2008). Model fit indices and item loadings were used to evaluate the configural invariance model. As depicted in Table 2, this model fit well (CFI $=0.96$, TLI $=0.95$, RMSEA $=0.04)$. Table 3 depicts the factor loadings of each item for each ERI group.

\section{Factorial and Threshold Invariance Testing}

The next steps in establishing MI are testing the invariance of factor loadings and thresholds. The categorical observed variables studied here entailed simultaneously testing factorial and threshold invariance rather than sequential tests of factorial then threshold invariance (Muthén \& Muthén, 2010; Schmitt \& Kuljanin, 2008). This requires that the factor loadings and thresholds (thresholds are similar to intercepts) are constrained as equal across ERI groups. This highly constrained model was then compared to the baseline configural invariance model (which allows loadings and thresholds to freely vary across ERI groups). All other things being equal, this highly constrained model would be expected to fit worse than a model where 
Table 3

Configural Invariance: Factor Loadings by Ethnic-Racial Identity Group

\begin{tabular}{|c|c|c|c|c|c|c|}
\hline \multirow[b]{2}{*}{ Latent variable and indicators } & \multicolumn{2}{|c|}{$\begin{array}{l}\text { Standardized } \\
\text { estimate }\end{array}$} & \multicolumn{2}{|c|}{$S E$} & \multicolumn{2}{|c|}{$\begin{array}{l}\text { Standardized } \\
\text { estimate/SE }\end{array}$} \\
\hline & Latino/a & $\begin{array}{l}\text { African } \\
\text { American }\end{array}$ & Latino/a & $\begin{array}{l}\text { African } \\
\text { American }\end{array}$ & Latino/a & $\begin{array}{l}\text { African } \\
\text { American }\end{array}$ \\
\hline \multicolumn{7}{|l|}{ Critical reflection: egalitarianism } \\
\hline $\begin{array}{l}\text { BS4G2 - All ethnic and racial groups should have equal } \\
\text { chances at education }\end{array}$ & 0.81 & 0.82 & 0.04 & 0.06 & $23.46^{*}$ & $14.89^{*}$ \\
\hline $\begin{array}{l}\text { BS4G5-All ethnic and racial groups should have equal } \\
\text { chances at jobs }\end{array}$ & 0.86 & 0.88 & 0.04 & 0.05 & $22.81^{*}$ & $17.21^{*}$ \\
\hline $\begin{array}{l}\text { BS4G8-Schools should teach students to respect members } \\
\text { of all ethnic and racial groups }\end{array}$ & 0.66 & 0.54 & 0.05 & 0.06 & $13.59^{*}$ & $9.30^{*}$ \\
\hline \multicolumn{7}{|l|}{ Critical reflection: perceived inequality } \\
\hline $\begin{array}{l}\text { BS4F1 - Children who are members of certain racial or ethnic } \\
\text { groups have fewer chances than other children to get a good } \\
\text { high school education in this country }\end{array}$ & 0.71 & 0.72 & 0.04 & 0.05 & $18.19^{*}$ & $15.99^{*}$ \\
\hline $\begin{array}{l}\text { BS4F3 - Children from poor families have fewer chances } \\
\text { than others to get a good high school education in this country }\end{array}$ & 0.78 & 0.72 & 0.03 & 0.05 & $23.06^{*}$ & $14.98^{*}$ \\
\hline $\begin{array}{l}\text { BS4F5-Adults who are members of certain racial or ethnic } \\
\text { groups have fewer chances than others to get good jobs in this } \\
\text { country }\end{array}$ & 0.75 & 0.75 & 0.04 & 0.04 & $19.77^{*}$ & $17.52^{*}$ \\
\hline $\begin{array}{l}\text { BS4F6-Women have fewer chances than men to get good jobs } \\
\text { in this country }\end{array}$ & 0.72 & 0.63 & 0.04 & 0.05 & $18.52^{*}$ & $11.73^{*}$ \\
\hline \multicolumn{7}{|l|}{ Internal political efficacy } \\
\hline BS4I2-I know more about politics than most people of my age & 0.55 & 0.67 & 0.05 & 0.05 & $11.44^{*}$ & $12.32^{*}$ \\
\hline $\begin{array}{l}\text { BS4I5-When political issues or problems are being discussed, } \\
\text { I usually have something to say }\end{array}$ & 0.62 & 0.55 & 0.05 & 0.07 & $11.48^{*}$ & $8.46^{*}$ \\
\hline BS4I8-I am able to understand most political issues easily & 0.67 & 0.49 & 0.04 & 0.06 & $15.49^{*}$ & $7.87^{*}$ \\
\hline BS4I10-I am interested in politics & 0.84 & 0.74 & 0.04 & 0.05 & $24.05^{*}$ & $14.48^{*}$ \\
\hline \multicolumn{7}{|l|}{ External political efficacy } \\
\hline $\begin{array}{l}\text { BS4I4 - The powerful leaders in government care very } \\
\text { little about the opinions of people }\end{array}$ & 0.40 & 0.39 & 0.07 & 0.09 & $5.53^{*}$ & $4.52^{*}$ \\
\hline $\begin{array}{l}\text { BS4I6 - In this country, a few individuals have a lot of } \\
\text { political power while the rest of the people have very little } \\
\text { power }\end{array}$ & 0.75 & 0.59 & 0.10 & 0.10 & $7.73^{*}$ & $5.70^{*}$ \\
\hline $\begin{array}{l}\text { BS4I7-The politicians quickly forget the needs of the voters } \\
\text { who elected them }\end{array}$ & 0.52 & 0.63 & 0.08 & 0.08 & $6.40^{*}$ & $7.86^{*}$ \\
\hline \multicolumn{7}{|l|}{ Expected conventional political action } \\
\hline BS5M3-Join a political party & 0.85 & 0.80 & 0.03 & 0.04 & $27.79^{*}$ & $19.88^{*}$ \\
\hline $\begin{array}{l}\text { BS5M4 -Write letters to a newspaper about social or political } \\
\text { concerns }\end{array}$ & 0.82 & 0.75 & 0.03 & 0.04 & $29.10^{*}$ & $18.76^{*}$ \\
\hline \multicolumn{7}{|l|}{ Expected voting } \\
\hline BS5M1-Vote in national elections & 0.85 & 0.85 & 0.03 & 0.07 & $31.38^{*}$ & $12.08^{*}$ \\
\hline $\begin{array}{l}\text { BS5M2 - Get information about candidates before voting in the } \\
\text { election }\end{array}$ & 0.90 & 0.75 & 0.02 & 0.08 & $38.26^{*}$ & $9.95^{*}$ \\
\hline \multicolumn{7}{|l|}{ Critical action: protest } \\
\hline $\begin{array}{l}\text { BS5M10-Do you expect that you will spray paint protest } \\
\text { slogans on walls in the near future? }\end{array}$ & 0.84 & 0.89 & 0.02 & 0.02 & $40.77^{*}$ & $39.81^{*}$ \\
\hline $\begin{array}{l}\text { BS5M11-Do you expect that you will block traffic as a form } \\
\text { of protest in the near future? }\end{array}$ & 0.94 & 0.92 & 0.02 & 0.02 & $55.68^{*}$ & $45.28^{*}$ \\
\hline $\begin{array}{l}\text { BS5M12-Do you expect that you will occupy public } \\
\text { buildings as a form of protest in the near future? }\end{array}$ & 0.88 & 0.90 & 0.02 & 0.03 & $42.23^{*}$ & $35.71^{*}$ \\
\hline
\end{tabular}

$* p<.05$. 
parameters are free to vary across groups (Kline, 2010). If the fit of the highly constrained factorial and threshold invariance model is not significantly worse than the configural invariance model, then evidence of factorial and threshold invariance is obtained, evidence of "strong" MI. The factorial and threshold invariance model was identified by fixing the first factor loading of each construct to 1 and constraining all other factor loadings to be equal across the two ERI groups, fixing scale factors to 1 and factor means to 0 in the Latino/a group, arbitrarily selected as the reference group (Kline, 2010; Muthén \& Muthén, 2010).

SEM fit indices and the chi-square difference test (corrected for categorical indicators) were considered in comparing the configural invariance model to the factorial and threshold invariance model. (In comparing the baseline and constrained models, a significant chi-square difference test is an indication of undesirable misfit for the constrained model.) As depicted in Table 2, model fit for the configural invariance $(\mathrm{CFI}=0.96$, $\mathrm{TLI}=0.95, \quad$ RMSEA $=0.04)$ and factorial and threshold invariance models (CFI $=0.96$, $\mathrm{TLI}=0.96$, RMSEA $=0.04)$ was nearly equal. The $p$ value of the chi-square difference test was .15 (where the significance criterion was .01), indicating that the highly constrained factorial and threshold invariance model was not significantly worse fitting than the configural invariance model -evidence of factorial and threshold invariance. As the conditions for MI were met, this is evidence that these measures are "strongly invariant" across these two ERI groups. This also establishes that the scaling of items is perceived similarly across groups and that these items have the same meaning and are interpreted in the same way across these two ERI groups (Kline, 2010).

\section{Structural Model: Unraveling Relations Among Critical Reflection, Efficacy, and Action}

The structural model tested hypothesized relations among latent constructs, as depicted in Figure 1, while controlling for civic/political knowledge (not depicted for clarity). The civic/ political knowledge covariate only predicted critical reflection: egalitarianism $(\beta=.49)$ and internal political efficacy $(\beta=.34)$ for the Latino/a group and only critical reflection: egalitarianism $(\beta=.38)$, expected voting $(\beta=.35)$, and critical action: protest $(\beta=-.45)$ for the African American group. (More information about nonsignificant paths from this covariate can be obtained from the first author.) Model fit indices indicated that the structural model was a good fit to the data $(\mathrm{CFI}=0.95, \mathrm{TLI}=0.94, \mathrm{RMSEA}=0.04)$. Complete structural model results are reported in Figure 2 and detailed below (key findings are highlighted in Table 4).

Contrary to study hypotheses, critical reflection: egalitarianism was not a significant predictor of internal political efficacy $\left(\beta_{\text {Latino/a }}=-.07 ; \beta_{\text {African }}\right.$ American $=-.03$ ) or of expected conventional political action $\left(\beta_{\text {Latino } / \mathrm{a}}=.10 ; \beta_{\text {African }}\right.$ American $\left.=.00\right)$. Critical reflection: egalitarianism was a significant predictor of expected voting for Latino/as $(\beta=.33)$, but not African Americans $(\beta=.05)$. Critical reflection: egalitarianism was a significant negative predictor of critical action: protest for the Latino/a group $(\beta=-.29)$, but not the African American group $(\beta=.10)$.

Critical reflection: perceived inequality did not significantly predict internal political efficacy for the Latino/a $(\beta=.10)$ or African American $(\beta=.00)$ groups. Critical reflection: perceived inequality was a significant but negative predictor of external political efficacy for both groups $\left(\beta_{\text {Latino/a }}=-.27\right.$; $\beta_{\text {African American }}=-.28$ ), such that those who perceived greater levels of societal inequality also felt that the government was less responsive to their interests. Critical reflection: perceived inequality was a significant predictor of critical action: protest for the Latino/a group $(\beta=.15)$ and African American group $(\beta=.20)$. For the Latino/a group, critical reflection: perceived inequality was not a significant predictor of expected conventional political action $(\beta=.06)$, but was for the African American group $(\beta=.31)$. Critical reflection: perceived inequality negatively predicted expected voting for the Latino/a group $(\beta=-.14)$, but the relation was nonsignificant for the African American group $(\beta=.10)$.

Internal political efficacy was a significant predictor of expected conventional political action for both the Latino/a $(\beta=.60)$ and the African American $(\beta=.65)$ groups, as well as of voting ( $\beta_{\text {Latino/a }}$ $=.44 ; \beta_{\text {African }}$ American $=.30$ ). Internal political efficacy was a significant predictor of critical action: protest for only the Latino/a group $\left(\beta_{\text {Latino/a }}=.22\right.$; $\beta_{\text {African }}$ American $=.14$ ). Contrary to expectations, external political efficacy was not a significant predictor of critical action: protest for either the Latino/a $(\beta=.02)$ or the African American $(\beta=.07)$ groups. Internal political efficacy correlated negatively with external political efficacy for both the Latino/a group $(\beta=-.31)$ and the African American group $(\beta=-.41)$. 


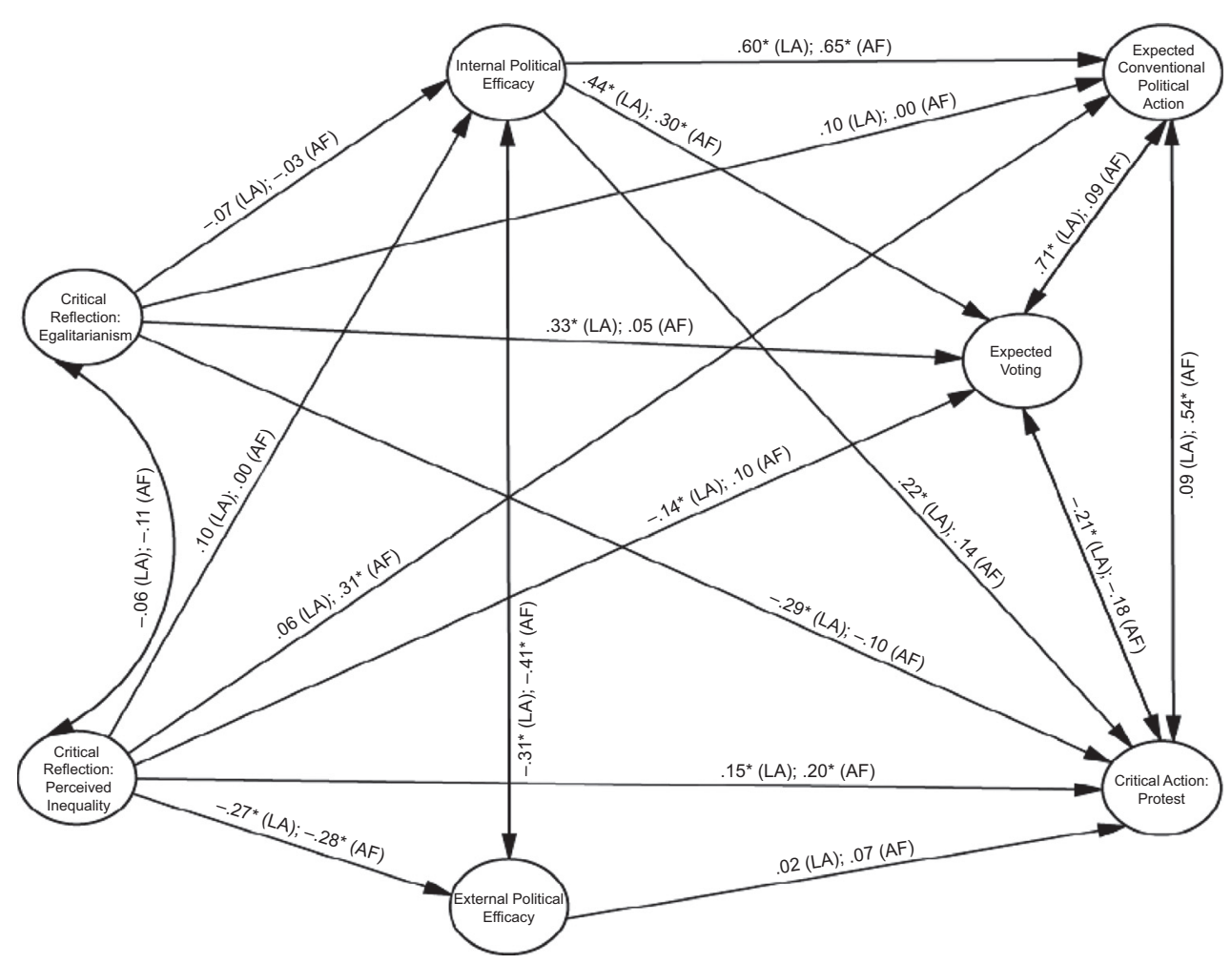

Figure 2. Structural model. LA = Latino/a and AF = African American.

*Statistically significant path coefficient.

Table 4

Overview of Paths

\begin{tabular}{|c|c|c|c|c|}
\hline \multirow[b]{2}{*}{ Path } & \multicolumn{2}{|c|}{ Latino/a } & \multicolumn{2}{|c|}{ African American } \\
\hline & $\begin{array}{l}\text { Standardized } \\
\text { estimate }\end{array}$ & $S E$ & $\begin{array}{l}\text { Standardized } \\
\text { estimate }\end{array}$ & SE \\
\hline Critical reflection: egalitarianism $\rightarrow$ Expected voting & 0.33 & 0.08 & 0.05 & 0.09 \\
\hline Critical reflection: egalitarianism $\rightarrow$ Critical action: protest & -0.29 & 0.08 & -0.10 & 0.08 \\
\hline $\begin{array}{l}\text { Critical reflection: perceived inequality } \rightarrow \text { Expected conventional } \\
\text { political action }\end{array}$ & 0.06 & 0.08 & 0.31 & 0.09 \\
\hline Critical reflection: perceived inequality $\rightarrow$ Expected voting & -0.14 & 0.06 & 0.10 & \\
\hline Critical reflection: perceived inequality $\rightarrow$ External political efficacy & -0.27 & 0.09 & -0.28 & 0.09 \\
\hline Critical reflection: perceived inequality $\rightarrow$ Critical action: protest & 0.15 & 0.07 & 0.20 & 0.08 \\
\hline Internal political efficacy $\rightarrow$ Expected conventional political action & 0.60 & 0.08 & 0.65 & 0.07 \\
\hline Internal political efficacy $\rightarrow$ Expected voting & 0.44 & 0.06 & 0.30 & 0.07 \\
\hline Internal political efficacy $\rightarrow$ Critical action: protest & 0.22 & 0.07 & 0.14 & 0.09 \\
\hline Expected voting with expected conventional political action & 0.71 & 0.06 & 0.09 & 0.13 \\
\hline Expected voting with critical action: protest & -0.21 & 0.08 & -0.18 & 0.09 \\
\hline Internal political efficacy with external political efficacy & -0.31 & 0.09 & -0.41 & 0.10 \\
\hline Expected conventional political action with critical action: protest & 0.09 & 0.08 & 0.54 & 0.10 \\
\hline
\end{tabular}

Note. Significant standardized estimates $(p<.05)$ are given in bold.

Expected conventional political action correlated with expected voting for the Latino/a group $(\beta=.71)$, but counter to hypotheses, it did not for the African American group $(\beta=.09)$. Expected voting correlated negatively with critical action: protest for the Latino/a group $(\beta=-.21)$, but this relation 
only approached significance for the African American group $(\beta=-.18)$. Expected conventional political participation and critical action: protest significantly correlated for the African American group $(\beta=.54)$, but not for the Latino/a group $(\beta=.10)$.

A series of mediating relations - that internal political efficacy mediates the relation between perceived inequality and expected social action, the relation between perceived inequality and conventional political action, and the relation between perceived inequality and expected voting - as well as whether external political efficacy mediates the relation between perceived inequality and expected social action-were tested. Of the "main effects" in these hypothesized mediating chains, only the relation between perceived inequality and external political efficacy was significant. However, the mediated relation between perceived inequality, external political efficacy, and expected social action was not significant.

In sum, critical reflection: egalitarianism did not predict internal political efficacy or expected conventional political action and predicted expected voting and critical action: protest only for the Latino/a group. Although critical reflection: perceived inequality did not predict internal political efficacy, it did predict critical action: protest for both the Latino/a group and the African American group. Critical reflection: perceived inequality also predicted external political efficacy. Contrary to expectations, critical reflection: perceived inequality predicted expected conventional political action for only the African American group and expected voting for only the Latino/a group. Internal political efficacy predicted expected conventional political participation and expected voting in accordance with study hypotheses, but predicted critical action: protest for only the Latino/a ERI group. External political efficacy did not predict critical action: protest. Finally, none of the hypothesized mediating relations were supported.

\section{Alternative Models: Does Political Efficacy Moderate the Reflection-Action Linkage?}

One affordance of SEM is the capacity to test substantively plausible alternative models. A series of alternative models tested these interaction relations - that internal political efficacy moderates the relation between perceived inequality and expected social action, the relation between perceived inequality and conventional political action, and the relation between perceived inequality and expected voting - as well as whether external political efficacy moderates the relation between perceived inequality and expected social action. These four interactions were independently examined in four separate analyses, due to the high computational demands and mathematical complexity of latent variable interactions (Muthén \& Muthén, 2010)particularly in complex SEM that analyzes categorical observed indicators with subpopulations, using a weighted data set (CIVED).

Unfortunately, none of these alternative models converged to an acceptable solution, and could not be interpreted, even after applying several remedies (e.g., increasing the number of iterations, modeling the interaction in different ways, and consulting the methodological literature and experts). We could not discern whether these problems were due to the complexity of these analyses or because the hypothesized moderating processes were simply not present. Specifying latent variable interactions where none exist may cause model nonconvergence (Kline, 2010).

Therefore, as a less precise test of this important substantive issue, a series of interaction terms were created from the sums of these observed variables. After mean centering all interaction terms, these processes were tested using multiple regression. However, none of these interactions were significant, failing to support the hypothesized moderating relations.

\section{Discussion}

This study examined whether the subcomponents of critical reflection differentially predict disparate forms of civic and political participation (i.e., protesting vs. voting vs. conventional political behavior) among marginalized adolescents. Second, this study examined whether internal and external political efficacy may play mediating or moderating roles in the relation between critical reflection and action. The CIVED data set, which uniquely measures all of these constructs and measures CC in a manner consistent with extant theoretical frameworks (Watts et al., 2011) and recently validated CC instruments (Diemer et al., 2014), was leveraged to provide more specific and nuanced answers to these questions - all while controlling for civic/political knowledge. Before addressing these two overarching questions, the MI of constructs was established across samples of lower socioeconomic status African American and Latino/a youth. This entails that these constructs are measured in the 
same way and mean the same thing across these ERI groups, and that comparisons of structural relations between these ERI groups are not biased by ethnic-racial measurement error.

Rather complex patterns of relations emerged in terms of how distinct components of CC relate to various forms of political action. While some of these relations emerged as expected for both ERI groups (e.g., critical reflection: perceived inequality predicted critical action: protest), a number of hypothesized relations did not (e.g., critical reflection: egalitarianism did not predict expected conventional political action). Other associations simply varied by ERI group. Finally, internal political efficacy did not mediate or moderate relations between each critical reflection subcomponent and disparate forms of political action.

\section{Differential Relations Between Critical Reflection Subcomponents and Political Action}

Critical reflection: egalitarianism and critical reflection: perceived inequality appear to be distinct aspects of critical reflection, as evinced by weak and nonsignificant correlations between these constructs in this study and in previous inquiry (Diemer et al., 2014). It may be that egalitarianism reflects a more mainstream ideology in the United States (i.e., "All men [sic] are created equal"). On the other hand, perceived inequality reflects some analysis and critique of systematic patterns of injustice in the United States, which stand in opposition to societal ethos of equal opportunity and a meritocracy. It may also be that some participants naively believe that society is already equal (e.g., "All ethnic and racial groups already do have equal chances at education") and endorse egalitarianism items from this perspective (e.g., "All ethnic and racial groups should have equal chances at education"). This naïve perspective may also explain the more limited association between egalitarianism and perceived inequality.

Furthermore, specifically examining the critical reflection: egalitarianism and critical reflection: perceived inequality subcomponents as predictors of disparate forms of political action advances scholarly understanding in at least five important ways. First, critical reflection: perceived inequality predicted critical action: protest for Latino/a and African American youth. This suggests that a careful analysis of structural inequalities may motivate marginalized youth to engage in activism to produce social change. This provides rigorous empirical support for the fundamental tenets of CC
(Freire, 1973, 1993) and sociopolitical development theories (Watts \& Flanagan, 2007; Watts et al., 1999), is consistent with previous research (Gordon, 2007; Taft, 2006; Westheimer \& Kahne, 2004) and supports related work that suggests, but does not empirically test, this relation (Youniss \& Yates, 1997). These findings also suggest that this core tenet of CC theory operates similarly across these two ERI groups. First establishing the MI of these constructs across African American and Latino/a participants, controlling for civic knowledge, and addressing measurement error via SEM, coupled with the nearly identical magnitude of this path coefficient across these ERI groups, provides more confidence (yet certainly not causal evidence) that this relation is similar across these two populations.

Decomposing CC and examining this subcomponent of critical reflection advances inquiry that has relied upon undifferentiated CC measures (e.g., Diemer, 2012; Fine, 1991; Thomas et al., 2014). Specifically examining how critical reflection: perceived inequality predicts later protest behavior also suggests inroads to foster social movement activism (e.g., collective protest) among marginalized youth. For example, community-based youth organizations and youth participatory action research programs that emphasize structural attributions for societal inequities may indirectly foster marginalized youth's participation in social movement activism to produce social change (Kirshner, 2009; Watts et al., 2011).

Second, critical reflection: perceived inequality had a complex pattern of relations to more conventional forms of political action and voting, with some nuances between ERI groups. Perceived inequality significantly predicted expected conventional political action, yet only for African Americans $(\beta=.31)$; the magnitude of this coefficient was also quite a bit smaller for Latino/as $(\beta=.06)$. Perceived inequality had a significant negative relation to expected voting for Latino/as $(\beta=-.14)$ and a nonsignificant, yet positive, relation for African Americans $(\beta=.10)$. Coupled with the relations between perceived inequality and expected social action reviewed above, these results collectively suggest that perceived inequality may motivate expectations for disparate forms of political action (i.e., both conventional and social movement activism) more so for African American youth than for Latino/a youth.

The unique historical and cultural significance of the ballot box and other forms of conventional political participation for African Americans (American Political Science Association, Task Force on 
Inequality and American Democracy, 2004) may explain why perceived inequality was not negatively related to voting (in contrast to Latino/as) and positively related to conventional political participation for African Americans. Legacies of disenfranchisement may lead African American youth who perceive structural inequalities to not disregard voting and to consider contact with elected officials as a mechanism to produce change.

By contrast, issues of citizenship and enfranchisement have particular cultural and social significance for Latino/as, in that Latino/a youth are more likely to be first- or second-generation immigrants than African American youth (Rivas-Drake et al., 2014). Accordingly, beliefs in the "American Dream," equal opportunity, and the merits of voting as well as other conventional forms of participation may be higher among Latino/a youth than among African American youth (American Political Science Association, Task Force on Inequality and American Democracy, 2004). This notion is evinced by inspection of the item means in Table 1, which reveals that Latino/as perceived lower levels of inequality than African Americans and endorsed egalitarianism more than African Americans. However, the CIVED study, conducted in 1999, predates current immigration policy debates and movements (e.g., "United We Dream" movement; the DREAM or Development, Relief and Education for Alien Minors, Act), which have only underscored the cultural and historical significance of these issues for many Latino/a youth (Flanagan, 2013). Subsequent studies should examine whether these historical and cultural shifts may also lead to shifts in the pattern between perceived inequality and political participation among Latino/as.

Third, and contrary to study hypotheses, critical reflection: egalitarianism did not predict expected conventional political action (e.g., writing letters to a newspaper about political issues) for either ERI group. Aspirational beliefs that society ought to be more equal do not appear to motivate marginalized youth to expect to engage in conventional political action. Although not a direct comparison, Diemer et al. (2014) observed a negative correlation between critical reflection: egalitarianism and a broader measure of sociopolitical participation (e.g., containing both conventional and nonconventional political action) among predominantly African American youth. Collectively, these results suggest that critical reflection: egalitarianism may not engender either conventional or transformational forms of political action-a premise that should be examined further in subsequent research.
Fourth, these findings suggest aspirational beliefs that society ought to be more equal may lead to a different form of conventional political participation - voting-among Latino/a youth. The capacity to examine different forms of political participation (voting vs. writing letters to elected officials) and to do so across ERI groups provides a more nuanced understanding of these relations. Critical reflection: egalitarianism predicted expected voting only for Latino/a participants; furthermore, the difference in magnitude of this path between ERI groups $(\beta=.33$ for Latino/as vs. $\beta=.05$ for African Americans) was notable. As noted earlier, significance of this relation only among Latino/as may reflect the greater likelihood of recent immigration or greater concerns about issues related to citizenship - and consequently more optimistic views of societal equality and voting - among this ERI group (Flanagan, 2013). Unfortunately, generation status or citizenship could not be examined with CIVED, to more directly test this notion.

Fifth, critical reflection: egalitarianism also had differential relations to critical action: protest for Latino/a $(\beta=-.29)$ and African American youth $(\beta=-.10)$, with this relation only significant for Latino/as. Broadly, aspirational beliefs that society ought to be more equal did not translate into participation in expected social movement activism for either group. This finding converges with negative associations between egalitarianism and a measure of participation that included both conventional and activist forms of participation among a sample of predominantly African American youth (Diemer et al., 2014).

In summary, this portion of the model suggests that perceived inequality was predictive of expected social action for both groups, and generally more predictive of disparate forms of political action for African American youth than for Latino/a youth. In general, egalitarianism was generally more predictive of conventional political behavior and voting for Latino/a youth than for African American youth. Through these findings, we can indeed begin to unravel the complexity of the relations among CC and distinct forms of political action for marginalized youth. For example, perceptions of inequality appear to play a larger role in fostering distinct forms of action than aspirational beliefs regarding how society should be. These differences may also simply reflect the domain-specific nature of human development - early adolescents develop in different domains at different rates. For example, youth may begin to perceive structural inequalities before feeling able to produce social and political 
change. Examining these associations cross sectionally with older adolescents or longitudinally across adolescence would shed light on the ontogenesis of each CC component.

\section{Does Political Efficacy Mediate or Moderate the Critical Reflection-Action Linkage?}

The second major contribution of this article was examining whether distinct forms of political efficacy (i.e., internal vs. external) mediate or moderate relations between the subcomponents of critical reflection, conventional political action, voting, and social action. The notion that agency, such as the perceived capacity to effect social and political change (internal political efficacy), serves as a key link between critical reflection and action is a central tenet of CC (Freire, 1993) and sociopolitical development theory (Watts et al., 1999). Yet, scant research has tested this notion. Before reviewing the results regarding these mediating or moderating processes, the "main effects" in these analyses are reviewed first.

\section{Critical Reflection Subcomponents as Predictors of Political Efficacy}

Egalitarianism had no relation to internal political efficacy for either ERI group, diverging from positive associations between egalitarianism and the perceived capacity to effect change among urban adolescents (Diemer, Kauffman, Koenig, Trahan, \& Hsieh, 2006). Because the present study controlled for civic and political knowledge while also more specifically decomposing the component parts of CC, we hold more confidence in these findingsyet this should be further examined.

Critical reflection: perceived inequality was not related to internal political efficacy for either ERI group. However, critical reflection: perceived inequality was significantly related to external political efficacy for both groups. This suggests that as youth perceived more structural causes for social disparities, they also viewed the government as less responsive to their group's interests (note that the external political efficacy items are keyed so that higher scores represent higher levels of perceived responsiveness). This finding is consistent with previous inquiry, suggesting that as marginalized people perceive more structural inequities, they believe that those in power are less invested in people with less power (Kahne \& Westheimer, 2006; Shingles, 1981). This pattern of associations is consistent with extant theory (Freire, 1993; Watts \& Flanagan, 2007) and sheds light on how marginalized people make attributions for societal disparities and also come to understand the government's role in addressing these disparities.

\section{Does Political Efficacy Mediate or Moderate the Critical Reflection-Action Linkage?}

Of the four mediating processes of interest, only the critical reflection: perceived inequality to external political efficacy "main effect" was statistically significant. However, external political efficacy did not mediate the relation between perceived inequality and expected social action. Furthermore, we failed to detect any significant moderating relations -when testing them at the latent or observed variable level. This is a notable divergence from extant theory (Freire, 1973, 1993) and contemporary conceptualizations of CC (Diemer et al., 2014).

Across the mediation and moderation analyses, the failure to support a central tenet of CC theorythat increased levels of critical reflection lead to agency, which leads to action-was unexpected. It may be that internal political efficacy was not comprehensively measured enough in CIVED to robustly test this question. It may also be that a different form of agency, such as a more generalized sense of efficacy, is a more appropriate intervening (whether mediating or moderating) variable - which should be examined in future inquiry. This may also reflect a developmental issue, in that internal political efficacy may only mediate (or, moderate) the relation between critical reflection and action among older adolescents and adults. Other factors, such as social identity, may mediate the relation between perceived inequality and critical action or may directly predict critical action (Watts et al., 2011). For example, developing an ERI that encompasses the collective struggle of one's ethnic or racial group may mediate the relations between perceptions of structural inequality and critical action and/or lead to critical action on behalf of one's ERI group (Flanagan, 2013; Shingles, 1981).

\section{Relations Between Political Efficacy and Disparate Forms of Political Action}

Internal political efficacy significantly predicted conventional political action and voting for Latino/a and African American youth, consistent with a large literature (e.g., American Political Science Association, Task Force on Inequality and American Democracy, 2004; Kahne \& Westheimer, 2006). Internal political efficacy also predicted critical action: 
protest among Latino/as (and approached significance among African Americans), consistent with a much more limited literature (e.g., Diemer \& Li, 2011). External political efficacy had no relation to expected social action for either ERI group, suggesting that perceptions that government is unresponsive do not translate into "taking matters into one's own hands" by engaging in social movement activism.

\section{Limitations and Future Directions}

The most notable limitation of this study was the reliance on self-reported expectations for future action (i.e., expected conventional political action, voting, and critical action: protest). Expectations for future participation may be more developmentally sensitive measures of sociopolitical participation among adolescents (e.g., Watts \& Flanagan, 2007), yet are likely more biased than reports of past action or triangulated reports from other informants. Diemer and Li (2011) observed some bias in self-reports of expected voting among marginalized youth, which suggests potential bias in these selfreport measures. This bias is attenuated by the use of SEM, which removes some of this bias from obtained estimates; establishing MI also rules out measurement differences across ERI groups (Kline, 2010). However, we would expect no such bias in the civic knowledge covariate, and only the CIVED data set afforded testing a complex theoretical model with such specific measurements. Yet, the reliance on self-reports about future participation is a limitation that should be acknowledged and addressed in future research.

CIVED richly measures individual and psychological variables regarding CC and different forms of sociopolitical participation, yet its measurement of the contextual features that may foster CC and participation is sparse. One CIVED item (the variable BCHUMANR) asks the school principal of these ninth-grade students, "Is a human rights organization available for students to join here in the school or community?" We tried to include this variable, as a thin measure of contextual support, in the model tested here yet were unable to do so. Presumably, this is because the BCHUMANR variable had a high degree of missing data (35\%) and what data points were present did not exhibit that much variation. Because adult mentorship and partnership with young people plays an important role in fostering CC as well as different forms of social and political action (Kirshner, 2009; Watts \& Flanagan, 2007), the inability to measure this and other features of context in this study is a limitation that should be addressed in future research.

Critical reflection and critical action: protest were ineludibly measured with different levels of specificity in CIVED. Yet, this dissimilarity may have attenuated estimates of the relations between these constructs. The critical reflection: perceived inequality and critical reflection: egalitarianism items assess views of specific issues (i.e., ethnic-racial, gendered, and socioeconomic constraints on educational and occupational opportunity), while the critical action: protest items do not specify specific injustices to be protested. For example, participants who expected to protest environmental issues or reproductive rights may have endorsed the critical action: protest items. Yet, these same participants would not necessarily have endorsed the critical reflection items regarding ethnic-racial, gendered, and socioeconomic constraints on opportunity. More general ways of assessing expected political and critical action in the future is more developmentally sensitive (Diemer \& Li, 2011; Watts \& Flanagan, 2007) while assessing critical reflection about specific issues is necessary, as questions such as "Is society fair?" are not specific enough to probe critical reflection (Watts et al., 2011). The mismatch between how the critical reflection and critical action items were measured in CIVED may have underestimated the "real" relation between these constructs. This could be addressed by examining this relation with older adolescents or young adults in future research, as measures of critical reflection and critical action could be more specifically aligned with older participants.

CIVED contributed several advantages to this study, yet only afforded testing these relations with samples of African American and Latino/a youth. CIVED did not contain large enough samples of other ERI groups, such Asian Americans, to be examined, which is a limitation. It is an open question whether these findings would generalize to other ERI groups, which have unique sociopolitical histories and cultural practices (Rivas-Drake et al., 2014) as well as unique structural constraints that limit conventional and social movement participation (Watts \& Flanagan, 2007). The obtained model was not examined with more privileged youth; it may hold or function differently among more privileged populations. Although CC is argued to be a less relevant construct for more privileged youth (Freire, 1993; Watts et al., 2011), a notion with some empirical support (e.g., Diemer et al., 2010), this remains a direction for future research. 
CIVED was a cross-sectional study of ninth graders, which suggests future research would benefit from further examining these issues longitudinally as well as replicating these findings with youth older than age 18, when many formal barriers to political and social movement participation are removed. It may be that the significance or magnitude of these relations would differ for youth across different developmental stages. The dynamic interplay among these CC components could also be better examined with longitudinal research, in that how participation in critical action may lead to greater levels of critical action over time could be examined, for example. Finally, CIVED was conducted in 1999 and current sociopolitical issues (e.g., immigration policy) may change the strength or pattern of relations of these analyses. Future research should replicate this nuanced examination of ethnic-racial heterogeneity and domain-specific forms of CC and political participation with more recent sources of data.

\section{Summary and Conclusions}

This research unraveled the nuanced relations between distinct dimensions of CC and distinct forms of political action among marginalized Latino/a and African American adolescents. After establishing MI across the Latino/a and African American ERI groups, analyses revealed complex patterns of associations between critical action: protest, political efficacy, and conventional political action. Central tenets of CC theory, such as perceptions of inequality associating with engagement in social action, were supported. Extant scholarship regarding the importance of internal political efficacy in predicting disparate forms of action was also supported. However, critical reflection: egalitarianism had a differential relation to expected voting across ERI groups and was not generally associated with efficacy, action, or the other component of critical reflection (perceived inequality). Furthermore, these analyses failed to support a central tenet of CC theory-that agency, in this case internal political efficacy-links critical reflection to critical action. As this is a central idea within this substantive framework, the failure to support them in this study is puzzling and raises a number of open questions. Future research should further test whether other forms of agency may mediate (or, moderate) relations between perceived inequality and social action among marginalized youth, in order to provide more empirical scrutiny of what is a canonical idea within CC scholarship.

\section{References}

American Political Science Association, Task Force on Inequality and American Democracy. (2004). American democracy in an age of rising inequality. Washington, DC: APSA.

Clark, L. A., \& Watson, D. (1995). Constructing validity: Basic issues in objective scale development. Psychological Assessment, 7, 309-319. doi:10.1037/1040-3590.7.3. 309

DeVellis, R. (2003). Scale development: Theory and applications. New York, NY: Russell Sage Foundation.

Diemer, M. A. (2012). Fostering marginalized youths' political participation: Longitudinal roles of parental political socialization on youth sociopolitical development. American Journal of Community Psychology, 50, 246-256. doi:10.1007/s10464-012-9495-9

Diemer, M. A., \& Blustein, D. L. (2006). Critical consciousness and career development among urban youth. Journal of Vocational Behavior, 68, 220-232. doi:10.1016/j.jvb.2005.07.001

Diemer, M. A., Kauffman, A. L., Koenig, N. B., Trahan, E. B., \& Hsieh, C. (2006). Challenging racism, sexism, and social injustice: Support for urban adolescents' critical consciousness development. Cultural Diversity and Ethnic Minority Psychology, 12, 444-460. doi:10.1037/10999809.12.3.444

Diemer, M. A., \& Li, C. (2011). Critical consciousness and political engagement among marginalized youth. Child Development, 82, 1815-1833. doi:10.1111/j.1467-8624. 2011.01650.x

Diemer, M. A., Mistry, R., Wadsworth, M. E., López, I., \& Reimers, F. (2013). Best practices in conceptualizing and measuring social class in psychological research. ASAP: Analyses of Social Issues and Public Policy, 13, 77113. doi:10.1111/asap.12001

Diemer, M. A., Rapa, L. J., Park, C., \& Perry, J. C. (2014). Development and validation of the Critical Consciousness Scale. Youth $\mathcal{E}$ Society. Advance online publication. doi:10.1177/0044118X14538289

Diemer, M. A., Wang, Q., Moore, T., Gregory, S., Hatcher, K., \& Voight, A. M. (2010). Sociopolitical development, work salience, and vocational expectations among low-SES African American, Latin American, and Asian American youth. Developmental Psychology, 46, 619-635. doi:10.1037/a0017049

Fine, M. (1991). Framing dropouts: Notes on the politics of an urban public high school. Albany: State University of New York Press.

Flanagan, C. A. (2013). Teenage citizens: The political theories of the young. Cambridge, MA: Harvard University Press.

Freire, P. (1973). Education for critical consciousness. New York, NY: Continuum.

Freire, P. (1993). Pedagogy of the oppressed. New York, NY: Continuum.

Godfrey, E. B., \& Grayman, J. K. (2014). Teaching citizens: The role of open classroom climate in fostering critical 
consciousness among youth. Journal of Youth and Adolescence, 43, 1-17. doi:10.1007/s10964-013-0084-5

Gordon, H. R. (2007). Allies within and without: How adolescent activists conceptualize ageism and navigate adult power in youth social movements. Journal of Contemporary Ethnography, 36, 631-688. doi:10.1177/ 0891241606293608

Husfeldt, V., Barber, C., \& Torney-Purta, J. (2005). Students' social attitudes and expected political participation: New scales in the enhanced database of the IEA Civic Education Study, College Park: Civic Education Data and Researcher Services, Department of Human Development, University of Maryland College Park.

Kahne, J., \& Westheimer, J. (2006). The limits of political efficacy: Educating citizens for a democratic society. PS: Political Science and Politics, 39, 289-296. doi:10.1017/ S1049096506060471

Kirshner, B. (2009). "Power in numbers": Youth organizing as a context for exploring youth civic identity. Journal of Research on Adolescence, 19, 419-440. doi:10.1111/ j.1532-7795.2009.00601.x

Kline, R. (2010). Principles and practice of structural equation modeling (3rd ed.). New York, NY: Guilford.

Muthén, L. K., \& Muthén, B. O. (2010). MPlus user's guide (6th ed.). Los Angeles, CA: Author.

Niemi, R. G., Craig, S. C., \& Mattei, F. (1991). Measuring internal political efficacy in the 1988 National Education Study. American Political Science Review, 85, 14071413. doi:10.2307/1963953

Rivas-Drake, D., Markstrom, C., Syed, M., Lee, R. M., Umaña-Taylor, A. J., Yip, T., . . . French, S. (2014). Ethnic and racial identity in adolescence: Implications for psychosocial, academic, and health outcomes. Child Development, 85, 40-57. doi:10.1111/cdev.12200

Schmitt, N., \& Kuljanin, G. (2008). Measurement invariance: Review of practice and implications. Human Resource Management Review, 18, 210-222. doi:10.1016/ j.hrmr.2008.03.003

Shadish, W. R., Clark, M. H., \& Steiner, P. M. (2008). Can nonrandomized experiments yield accurate answers? A randomized experiment comparing random and nonrandom assignments. Journal of the American Statistical Association, 103, 1334-1344. doi:10.1198/ 016214508000000733
Shingles, R. D. (1981). Black consciousness and political participation: The missing link. American Political Science Review, 75, 76-91. doi:10.2307/1962160

Streiner, D. L. (2003). Starting at the beginning: An introduction to coefficient alpha and internal consistency. Journal of Personality Assessment, 80, 99-103. doi:10.1207/S15327752JPA8001_18

Taft, J. K. (2006). "I'm not a politics person": Teenage girls, oppositional consciousness, and the meaning of politics. Politics E Gender, 2, 329-352. doi:10.1017/ S1743923X06060119

Thomas, A. J., Barrie, R., Brunner, J., Clawson, A., Hewitt, A., Jeremie-Brink, G., \& Rowe-Johnson, M. (2014). Assessing critical consciousness in youth and young adults. Journal of Research on Adolescence, 24, 485-496. doi:10.1111/jora.12132

Torney-Purta, J., Lehmann, R., Oswald, H., \& Schulz, W. (2001). Citizenship and education in twenty-eight countries: Civic knowledge and engagement at age fourteen. Amsterdam, Netherlands: International Association for the Evaluation of Educational Achievement.

Watts, R. J., Diemer, M. A., \& Voight, A. M. (2011). Critical consciousness: Current status and future directions. New Directions for Child and Adolescent Development, 134, 43-57. doi:10.1002/cd.310

Watts, R. J., \& Flanagan, C. (2007). Pushing the envelope on youth civic engagement: Developmental and liberation psychology perspective. Journal of Community Psychology, 35, 779-792. doi:10.1002/jcop.20178

Watts, R. J., Griffith, D. M., \& Abdul-Adil, J. (1999). Sociopolitical development as an antidote for oppression-Theory and action. American Journal of Community Psychology, 27, 255-271. doi:10.1023/A:1022839818873

Westheimer, J., \& Kahne, J. (2004). What kind of citizen? The politics of educating for democracy. American Educational Research Journal, 41, 237-269. doi:10.3102/ 00028312041002237

Westland, J. C. (2010). Lower bounds on sample size in structural equation modeling. Electronic Commerce Research and Applications, 9, 476-487. doi:10.1016/ j.elerap.2010.07.003

Youniss, J., \& Yates, M. (1997). Community service and social responsibility in youth. Chicago, IL: University of Chicago Press. 